\title{
Humanitarian and primary healthcare needs of refugee women and children in Afghanistan
}

\author{
Ariel Higgins-Steele ${ }^{1,4^{*}}$, David Lai ${ }^{2}$, Paata Chikvaidze ${ }^{2}$, Khaksar Yousufi $^{1}$, Zelaikha Anwari ${ }^{3}$, Richard Peeperkorn ${ }^{2}$ \\ and Karen Edmond ${ }^{1}$
}

\begin{abstract}
This Commentary describes the situation and healthcare needs of Afghans returning to their country of origin. With more than 600,000 Afghans returned from Pakistan and approximately 450,000 Afghans returned from Iran in 2016, the movement of people, which has been continuing in 2017, presents additional burden on the weak health system and confounds new health vulnerabilities especially for women and children. Stewardship and response is required at all levels: the central Ministry of Public Health, Provincial Health Departments and community leaders all have important roles, while continued support from development partners and technical experts is needed to assist the health sector to address the emergency and primary healthcare needs of returnee and internally displaced women, children and families.
\end{abstract}

Keywords: Refugees, Returnees, Afghanistan, Women, Children

\section{Commentary}

While much attention understandably focuses on refugees and migrants entering Europe, many Afghan children, women and their families are forcibly or voluntarily returning to Afghanistan from Europe and neighbouring countries, including Pakistan and Iran. Commonly called 'returnees', these mothers and children are among the most vulnerable of all refugees, requiring support and investment across sectors, particularly for health. In 2016, more than 600,000 Afghans returned from Pakistan, whereas approximately 450,000 Afghans returned from Iran (Fig. 1) [1, 2]. Further, in addition to the returnees, there is a large group of internally displaced persons (IDPs) in Afghanistan. All regions in Afghanistan have been affected by the conflict and therefore 1500 people per day, on average, are forced to leave their homes to escape violence. In the first quarter of 2017, there were approximately 68,000 newly IDPs in the country $[3,4]$. With no foreseen improvements in security, 450,000 new IDPs and approximately 1 million returnees from Pakistan alone are expected in 2017 [1].

\footnotetext{
*Correspondence: ahiggins@unicef.org

'UNICEF Afghanistan Country Office, Kabul, Afghanistan

${ }^{4}$ UNICEF Afghanistan, United Nations Office Complex in Afghanistan

(UNOCA), Jalalabad Road, Kabul, Afghanistan

Full list of author information is available at the end of the article
}

Due to the ongoing conflict in Afghanistan, both returnees and IDPs require routine primary healthcare as well as emergency health services. Recent estimates suggest that more than 7 million people have no or limited access to essential health services due to insufficient coverage by the public health sector and direct interruption due to conflict and insecurity $[1,5]$. Immediate health needs support for refugee and IDP children, women and their families in Afghanistan includes vaccines (including poliovirus and measles vaccine), management of malnutrition, antibiotic treatment of infections, screening for tuberculosis, and prevention and care of sexually transmitted infections and HIV infection. Additionally, practical supplies, such as shelter, food, clothing, cash transfers, hygiene kits, insecticide treated nets and cash transfers for food and basic household items, are also required. Pregnant women (approximately $4.2 \%$ of the general population) require antenatal care, clean delivery kits and skilled delivery care. It is estimated that $10-15 \%$ of deliveries in Afghanistan will face complications and will require surgical intervention and safe blood transfusion. Skilled postnatal care for mothers and their newborns, as well as supplies and counselling for emergency and postpartum family planning are also needed. 


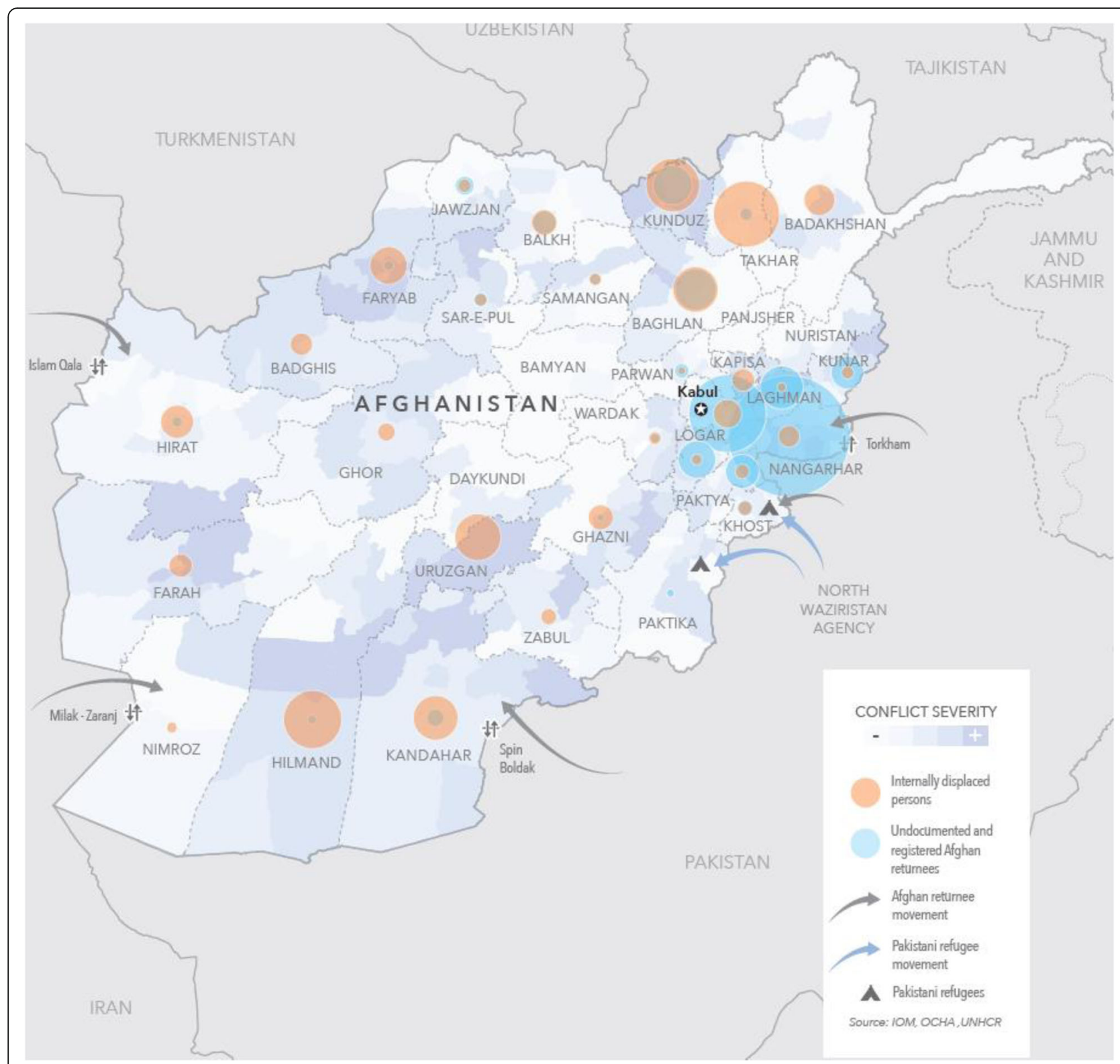

Fig. 1 Population movement in Afghanistan (source: IOM, OCHA, UNHCR 2017)

Coordination of the essential emergency health services in Afghanistan is being provided by the Health Cluster, led by the Ministry of Public Health and the World Health Organization with support from various partners. Encashment centres are one point of contact where support is delivered, as well as through zero points (at national borders), fixed health centres and mobile health teams. Yet, there are many challenges in providing an appropriate health sector response to women and children in Afghanistan. Afghanistan has a severely under-resourced public health system; while there have been improvements, the geographic distribution of health centres in the country is uneven and many families and pregnant women live more than 2 hours walking distance from a health facility [6]. For example, only approximately $50 \%$ of all pregnant women in Afghanistan deliver their babies in a health facility with a skilled attendant in contrast to the $70-80 \%$ rates reported in many low-income countries [6, 7]. Further, much of Afghanistan is mountainous and conflict in many areas of the country is increasing, additionally hampering access of vulnerable children and women to life-saving health services. Health facilities are understaffed, with few female staff, including night duty workers, vaccinators and nurses to provide maternal and newborn care. Financial pressures and conflict are causing 
returnee and internally displaced families to be constantly 'on the move' across Afghanistan. Children and their mothers are likely to miss important follow-up medical appointments and treatment. In addition, unlike other refugees, families who arrive in Afghanistan may experience a more violent, unstable and stressful environment than in their country of departure. This situation contributes to the financial, physical and emotional 'shocks' that Afghan refugee families face.

Indeed, the large numbers of families arriving are now pushing Afghanistan's health system to its limits, especially in the host communities (Fig. 2). An assessment undertaken in April 2017 in Nangarhar, a province bordering Pakistan, found that the caseload of in-patient departments in the regional hospital had increased by $27 \%$ and outpatient consultations had increased by $41 \%$ compared to the same period in 2016 [8]. In the same assessment, the district hospital bed occupancy rate was reported to be beyond the maximum range of $100 \%$. In particular, the paediatric and maternity ward average bed occupancy rates from January to March 2017 were 145\% and 115\% per month, respectively (Personal communication with Nangarhar Province Department of Health, May 2017).

\section{Conclusion}

Stewardship and response is required at all levels; the Ministry of Public Health, Provincial Health Departments and community leaders all have important roles. Continued support from development partners and technical experts is needed to assist the health sector to address the emergency and primary healthcare needs of returnee and internally displaced women, children and families. Mental

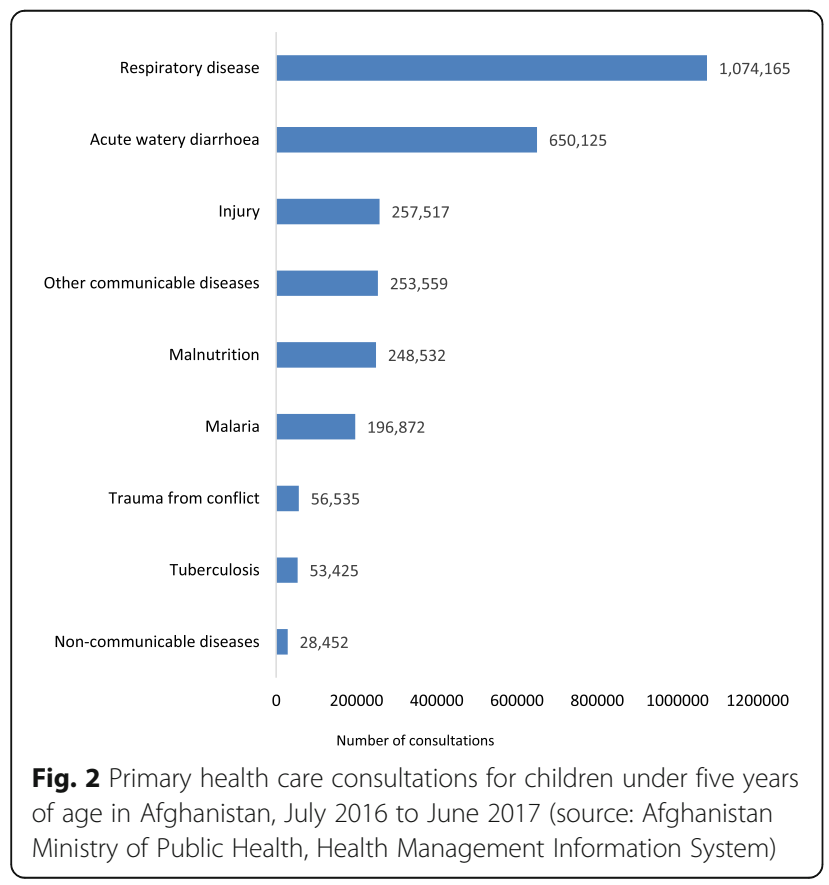

healthcare, emotional support, and child and family protection are additional but critical needs in a country already struggling to provide basic emergency and primary healthcare for its most vulnerable populations.

Funding

None.

Availability of data and materials

Not applicable.

\section{Authors' contributions}

AHS and KE drafted the commentary. DL and PC contributed and checked most recent data. All authors provided substantive inputs on context and recommendations of the commentary during several rounds of revisions. All authors read and approved the final manuscript.

\section{Authors' information}

All authors are working with government or United Nations organizations based in Kabul, Afghanistan with the aim of improving access to quality healthcare. Opinions expressed in this Commentary are their own. ZA is the Director for Reproductive, Maternal, Newborn, Child, and Adolescent Health Directorate at the Afghanistan Ministry of Public Health. KE, KY, and AHS are working with UNICEF's health programme on maternal and child health, with a focus on access to and demand for primary healthcare. RP, PC, and $\mathrm{DL}$ are with the World Health Organization and working to strengthen health services, address public health issues, and support and promote research for health in the country.

Ethics approval and consent to participate Not applicable.

Consent for publication

Not applicable.

Competing interests

The authors declare that they have no competing interests.

\section{Publisher's Note}

Springer Nature remains neutral with regard to jurisdictional claims in published maps and institutional affiliations.

\section{Author details}

${ }^{1}$ UNICEF Afghanistan Country Office, Kabul, Afghanistan. ${ }^{2}$ World Health Organization Afghanistan, Kabul, Afghanistan. ${ }^{3}$ Afghanistan Ministry of Public Health, Kabul, Afghanistan. ${ }^{4}$ UNICEF Afghanistan, United Nations Office Complex in Afghanistan (UNOCA), Jalalabad Road, Kabul, Afghanistan.

Received: 29 August 2017 Accepted: 18 October 2017

Published online: 11 December 2017

\section{References}

1. OCHA. Afghanistan: Humanitarian Needs Overview 2017. 2016. https://data. humdata.org/dataset/afghanistan-humanitarian-needs-overview-2017. (Accessed 10 October 2017).

2. Relief International. Returnees and Deportees in Nimroz: Needs Assessment Report. May 2017. [Report not currently available in public domain].

3. OCHA. Afghanistan: Humanitarian Response Plan 2017. 2017. https://www. humanitarianresponse.info/en/operations/afghanistan/infographic/ afghanistan-humanitarian-response-plan-2017-overview. (Accessed 10 October 2017).

4. International Organization for Migration. Return of Undocumented Afghans from Pakistan and Iran. 2017. https://afghanistan.iom.int/pakistan-returns. (Accessed 10 October 2017).

5. ACF International. Afghanistan: Where Humanitarian Concerns Do Not Match International Action. 2016. http://www.acbar.org/upload/ 1471410588562.pdf, Accessed 10 October 2017.

6. Central Statistics Organization. Afghanistan Living Conditions Survey 201314. National Risk and Vulnerability Assessment. 2016. http://cso.gov.af/en/ page/1500/1494/nrav-report. (Accessed 10 October 2017). 
7. Joesph G, da Silva IC M, Wehrmeister FC, Barros AJD, Victora CG. Inequalities in the coverage of place of delivery and skilled birth attendance: analyses of cross-sectional surveys in 80 low and middle-income countries. Reprod Health. 2016:13:77.

8. Personal communication with Nangarhar Province Department of Health. May 2017.

Submit your next manuscript to BioMed Central and we will help you at every step:

- We accept pre-submission inquiries

- Our selector tool helps you to find the most relevant journal

- We provide round the clock customer support

- Convenient online submission

- Thorough peer review

- Inclusion in PubMed and all major indexing services

- Maximum visibility for your research

Submit your manuscript at www.biomedcentral.com/submit 